\title{
The Business Model Study on Red Collar Group: Based on the Perspective of Blue Ocean Strategy
}

\author{
Yinghan Lv \\ Management School, Jinan University, Guangzhou, China \\ Email:547460313@qq.com
}

How to cite this paper: Lv, Y. H. (2017). The Business Model Study on Red Collar Group: Based on the Perspective of Blue Ocean Strategy. Chinese Studies, 6, 123131.

https://doi.org/10.4236/chnstd.2017.62011

Received: April 10, 2017

Accepted: May 20, 2017

Published: May 23, 2017

Copyright $\odot 2017$ by author and Scientific Research Publishing Inc. This work is licensed under the Creative Commons Attribution International License (CC BY 4.0).

http://creativecommons.org/licenses/by/4.0/

\begin{abstract}
Blue Ocean Strategy is a book published in 2005 and written by W. Chan Kim and Renée Mauborgne. The article analyzes the value innovation of red collar group in Shandong province based on the perspective of blue ocean strategy, using the four actions framework and the strategy canvas as the analysis tools to study the business model of red collar group. It is found that red collar group creates an intelligent platform with mass customization, and opens up a blue ocean of mass customization. The business model of red collar provides some reference for the transformation of traditional clothing manufacturing enterprises.
\end{abstract}

\section{Keywords}

Blue Ocean Strategy, Business Model, Red Collar Group, Value Innovation

\section{The Main Concepts}

\subsection{Blue Ocean Strategy}

Blue Ocean Strategy is a book published in 2005 and written by W. Chan Kim and Renée Mauborgne. They believe that it will be more and more difficult to create profitable growth in the future if the enterprise lingers in the competition of "red ocean". Enterprises can't compete with rivals, but to create a "blue ocean" to gain great development. The red ocean represents all of the industries existing, namely, the market space that we have known. The blue ocean represents the industries which don't exist, namely, the market space that we haven't known. The "Blue Ocean Strategy" uses quantitative way to investigate how to affect the revenue and profits of an enterprise by creating a blue ocean. The result is shown in Figure 1 (Kim \& Mauborgne, 2005). 


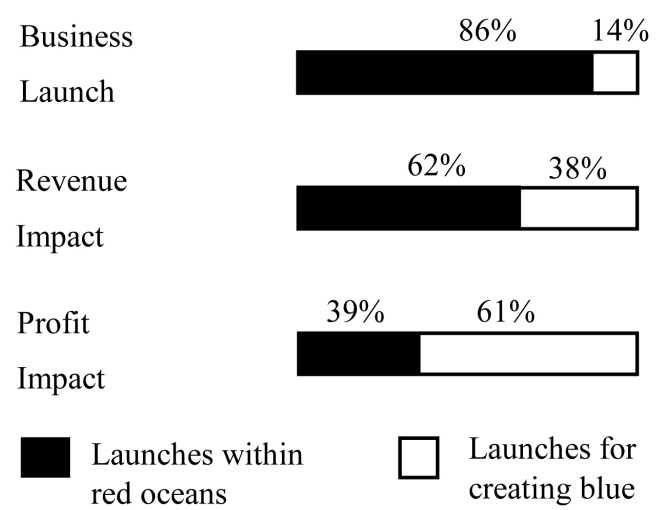

Figure 1. The profit and growth consequences of creating blue oceans.

They found that 86 percent of the launches accounted for only 62 percent of total revenues and a mere 39 percent of total profits. The remaining 14 percent of the launches were aimed at creating blue oceans. They generated 38 percent of total revenues and 61 percent of total profits. The effect of creating blue ocean on revenues and profit growth is obvious.

The boundaries and competition rules of the industries have been widely accepted and approved in red ocean. Dividing the cake of the market, the more crowded the market is, the more dismal the enterprise's future is. As the products are changed into goods, the cruel competition among the industries makes the red ocean bloody. In contrast, blue ocean represents the need to develop new market space and the opportunities of highly profit. And lots of the blue ocean is created from the red. The red collar group which is analyzed in this paper creates the blue ocean to break the bottleneck of the original clothing manufacturing.

\subsection{The Business Model}

Since 1990s, the emergence of the Internet has changed the basic of the business competitive environment and economic rules. A lot of companies based on the Internet emerged, such as Amazon, Yahoo, etc. Their ways to profit are different from other traditional enterprises. The term of business model became popular. Since the 21st century, the application of business model has not only been confined to the Internet, but also extended to other areas. It got extensive attention to commercial circles and scholars. The importance of the business model becomes prominent. The father of modern management, Peter F. Drucker, pointed that the competition of the enterprises today is not the product, but the business models. While the business model has not been defined clearly in academia up to now. The most recognized definition is proposed by Alexander Osterwalder et al. It says the business model is a kind of tool which contains a series of elements and relations among them, which is used to illustrate a particular entity's business logic (Chai Chunlei, Qiu Yiwu, \& Yu Liying, 2014). This paper is to analyze the business logic of the red collar group, and to summarize the enlightenment on the business model of it. 


\subsection{Blue Ocean Strategy and Business Model}

Official representative and spokesman of blue ocean strategy in China, Ji Mi, had a research of the theory of value innovation with W. Chan Kim and Renée Mauborgne. And she participated in the redaction of the book, Blue Ocean Strategy, from beginning to the end. She have pointed that if the ability to make high profit is the standard to measure a good business model, and then we can say that the blue ocean strategy is a powerful way to open up a good business model (Ji Mi, 2007). The enterprise in this article had made more than 150 percent growth of the profit. It can be regarded as a representation of a good business model. We don't use the blue ocean strategy to solve questions, but to study how to open up the blue ocean of the traditional clothing manufacturing enterprise from red collar by analytical tools and frameworks of blue ocean strategy.

\section{Case Description}

Red collar (RC) group in Qingdao was founded in 1995. It is a professional clothes production enterprise which produces suits, shirts, toolings and other series clothing. $\mathrm{RC}$ group has built more than 300 stores which have the unified image and formal management across the whole of China, and there are three subsidiaries, fifteen branches, five foreign branches and two industrial parks belong to RC. The income of custom business and net profit increased 100 percent above, and profit margin increased more than 25 percent in 2014 and 2015. In contrast, the public company of clothing industry's revenue growth of -2.6 percent in 2014 overall. The profit margin has increased 6 percent and net profit has increased -3.6 percent.

RC began to accept custom clothing orders in 2003 and started the plan to construct the personalized clothing system platform. RC began to change the business model from scaled and mass production to mass customization production at the same time. Now RC group has formed a C2M customization platform which is customer-oriented. RC have explored the path of the mass production of personalized customization for Chinese clothing enterprises.

\section{Analytical Tools and Frameworks of Blue Ocean Strategy}

\subsection{Value Innovation of Blue Ocean Strategy}

Creating the blue oceans shouldn't regard the competitor as their benchmark. Instead, the creators followed a different strategic logic called value innovation. Value innovation is the cornerstone of blue ocean strategy. Instead of focusing on beating the competition, to make the cake bigger, we focus on innovating a broader market space where nobody has done to get out of the limitation of the red sea and to escape from the competition completely. In the face of enterprise competition, general managers were in dilemma. The pursuit for the satisfaction of the consumer will increase the cost to realize differentiation to retain customers. The pursuit for low-cost and high profits will give up part of consumers which are difficult to satisfy, that is, give up a certain market space. The strategy 
is to make a choice between differentiation and low cost (Xu Ting, Chen Libiao, \& Cheng Shuping, 2007). Creating a blue ocean, however, is the pursuit of "differentiation" and "low cost" simultaneously. When a firm's strategic actions can not only play a positive role in cost structure, but also realize the value of buyers, the firm is in the value innovation.

\subsection{The Four Actions Framework of Blue Ocean Strategy}

Creating blue ocean is to break the balance of differentiation and low cost. It is the process to look for business model innovation, that is the process to complete the four actions framework as Figure 2 (Kim \& Mauborgn, 2005).

The process to solve the "Eliminate" and "Reduce" are the processes of cost reduction. The process to complete the course of "Raise" and "Create" are the processes of looking for differentiation. The whole process is to pursue "low cost" and "differentiation" at the same time, that is the process to realize value innovation.

\subsection{The Strategy Canvas of Blue Ocean Strategy}

The strategy canvas is both a diagnostic and an action framework. According to the strategy canvas, you can catch the known market competition situation intuitively. This allows you to understand where the competition is investing and which factors are the focuses of this industry currently. The horizontal axis captures the elements in the process of production. The longitudinal axis is the price. Connect all of the elements, and you will get the strategic profiles or value curves of the enterprises. As an essential part of the strategic canvas, value curves

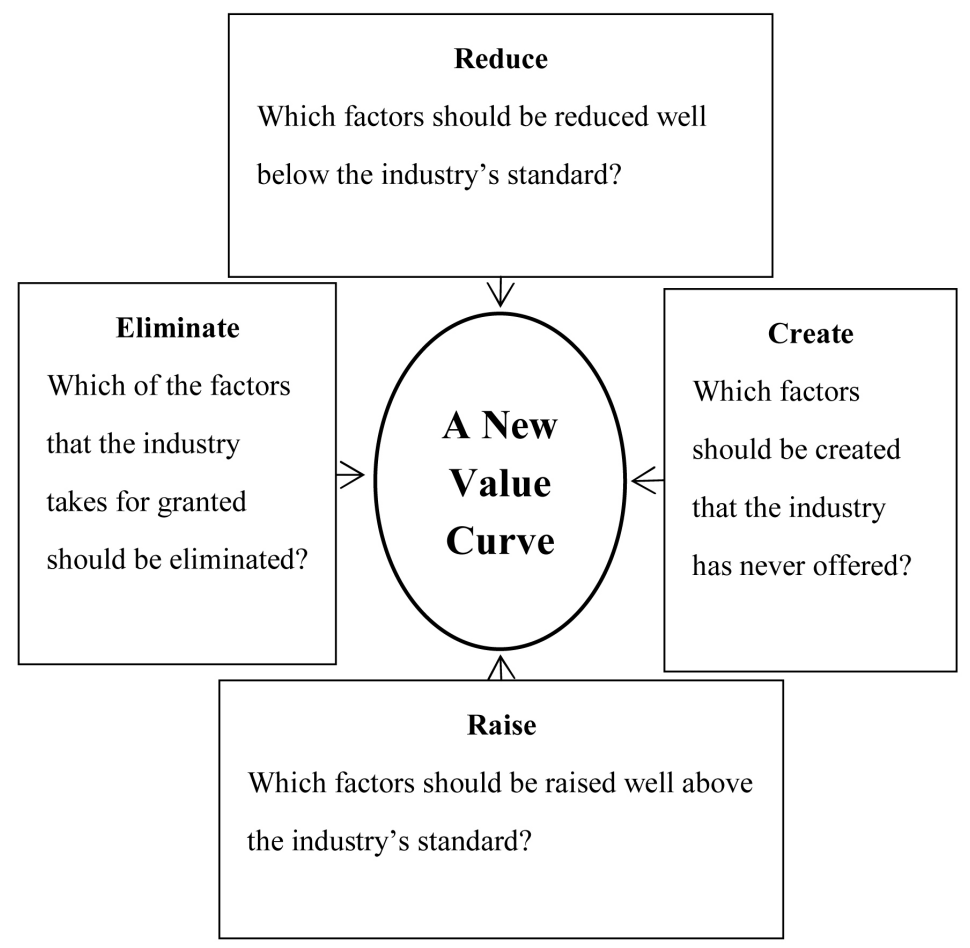

Figure 2. The four actions framework. 
depict the relative degree of each element in production graphically. The part four of the article will use the four actions framework and strategy canvas to analyze the business model of red collar group.

\section{Case Analysis}

\subsection{C2M Business Model}

C2M (Customer to Manufactory) customized business model means that the factory produces according to the customer's personalized orders. C2M platform is the online portal for customer to login through the use of mobile phones, etc. It can choose the designs of products, technology, raw materials and so on. The order is formed after online payment, then it was presented and completed through the platform. In the customization process of the past, customers transmit information by phone and fax, and it is difficult to make manufacturing workers understand customers' needs completely. C2M business model reduces the intermediate links between the consumer and manufacturing factory, thus reduces the intermediate links costs. It meets the personalized needs of customers which can serve them better (Liu Meiqi \& Zhang Yuting, 2015).

On-demand production achieves zero inventory. The customer can get the maximum benefit, and they don't need to share the inventory cost with enterprises. The cost ratio of customization and large-scale production is 1.1:1 in RC, that is, the cost to produce 100 pieces of clothing in custom is the same as produce 110 pieces of clothing in large-scale, but the profit is twice.

\subsection{Source Point Theory}

RC formed "source point theory" management thoughts to support new forms and new mode in transition. "Source" refers to "vision", and it also refers to the "demand" from the strategy. Source point theory refers to that all of the behaviors regard requirements as the source point and to integrate resources of value chain to meet the demand of source point eventually. The source point of RC is the customer, and to meet the demand of source point, that is to meet customer's demand. Applying source point theory to enterprise is the process to drive manufactory $(\mathrm{M})$ to meet customer $(\mathrm{C})$ demands according to their own opinions. This is congruent with the meaning of $\mathrm{C} 2 \mathrm{M}$ actually.

Based on the idea of the source point theory, RC remodels the organization structure. The original hierarchical structure was merged into six big center platform. The management cuts staff and department to form node management model which regards customer call center as the hub. Each node in the organization is responsible for each client node outside the organization, and the standard of the performance appraisal is the degree of meeting the source point. Without traditional management, two nodes can be polymerized freely. The position of manager is still exist, but the function is more about service and support (Pan Dongyan, 2014). The transformation of the source point theory makes the management cost decreased by 20 percent (Xie Dandan, 2016; Anonymous, 2016b). 


\subsection{Intelligent System}

The process from receiving the order to final delivery in $\mathrm{RC}$ depends on data-driven. E-business platform takes personalized order from customer first, then outputs the order by comparing the CAD data, divides the order to each employee according to the level of technology and skills, and groups together at last.

The data in the system meets all kinds of customization as far as possible through updating and integrating nearly ten years. Such as how to deal with the order for a hump, the system can't handle well at the first time, while the data will perfect automatically according to the information of the hump last to make the system better. Digital system of RC will become stronger gradually in constant update.

The system uses chip card as its carrier to acquire data about person, material or the other relevant information, and it is unified into the digital platform for the Internet of things through the organic integration of all nodes. The system was formed under the unified standard management with the coordination of production, logistics and business. The production cycle of made-to-order is about 3 - 6 months previous, and the price is about $1-20,000$ yuan lowest. The production cycle of RC to customize lasts for 7 working days longest from order to delivery, and the price is about 2000 yuan at least (Zhou Luhan, 2015). Patterning and plate-making one or two clothing needs one day in the past, while only needs 5 minutes of each pattern now. With the establishment of intelligent system, the production cycle was shorten greatly. One pattern of one person can meet the personalized need of customers quickly to improve the production efficiency.

\subsection{The Four Actions Framework}

According to the description and analysis above, the four actions framework of the model of RC is as follows.

Eliminate: RC model eliminated the intermediate steps between the consumer and manufacturing factory.

Reduce: On-demand production reduced the inventory cost of RC. Node management from point to point reduced the management cost. Intelligent system reduced the design cost for personalization, and the production cycle was shorten at the same time. The price for custom decreased with the cost of production reducing. As a result, customized is no longer the choice for high-end personage only.

Raise: The platform for big data of RC enhanced the productivity of the enterprise.

Create: The differentiation and scale are co-exist in the model of $\mathrm{RC}$ to realize the mass customization. The platform for big data matches the order of customers and splits the process of production to suitable workers automatically. The intelligent system has been realized as the organic integration of production, logistics and commerce. 
Put the four actions framework into the eliminate-reduce-raise-create grid (see Figure 3).

Eliminating the intermediate steps between the consumer and manufacturing factory and reducing the inventory cost, management cost, production cycle and custom price are two actions to reduce the cost. The processes to make the enterprise different with others are enhancing the productivity, and creating mass customization to realize the intelligent system. This is the value innovation of RC.

\subsection{The Strategy Canvas}

Strategy canvas is one of the analysis tools of the blue ocean strategy and the value curve is part of the strategy canvas. The advantage of low cost for OEM is reduced gradually. A large number of inventories caused a lot of traditional clothing enterprises cannot make ends meet. The customized strategy of traditional manual custom factory has attracted some high-end customers, but the high cost and the long circle for custom make it can't be universal. There are the value curves of the traditional manual custom factory, OEM factory and RC in Figure 4 according to collection and analysis of the data.

$\mathrm{RC}$ combined the strategy of mass from OEM with the customization from traditional manual custom factory and created a new model called mass customization. This is a new direction of OEM. And the large-scale production reduces the cost of custom at the same time. RC is not the enterprise only for clothing, but the one has grasped a new methodology. At present, the RC has already started to work with some traditional enterprises through copying the business model of RC to make them realize the rapid transformation and development (Anonymous, 2016a).

\section{Conclusion and Implications}

According to the study, we have found that the RC created a blue ocean of mass customization according to the four actions. The four actions in RC are breaking the balance of differentiation and low cost, eliminating the intermediate link between the consumer and manufacturing plants, reducing the custom cost, inventory cost, management cost and production cycle, and improving the

\begin{tabular}{|l|l|}
\hline Low Cost & Differentiation \\
\hline $\begin{array}{l}\text { Eliminate } \\
\text { the intermediate steps between the } \\
\text { consumer and manufacturing factory }\end{array}$ & $\begin{array}{l}\text { Raise } \\
\text { enhances productivity }\end{array}$ \\
\hline $\begin{array}{l}\text { Reduce } \\
\text { inventory cost } \\
\text { management cost } \\
\text { production cycle }\end{array}$ & $\begin{array}{l}\text { Create } \\
\text { personalization } \\
\text { Custom price }\end{array}$ \\
\hline
\end{tabular}

Figure 3. Eliminate-reduce-raise-create grid: the case of red collar. 


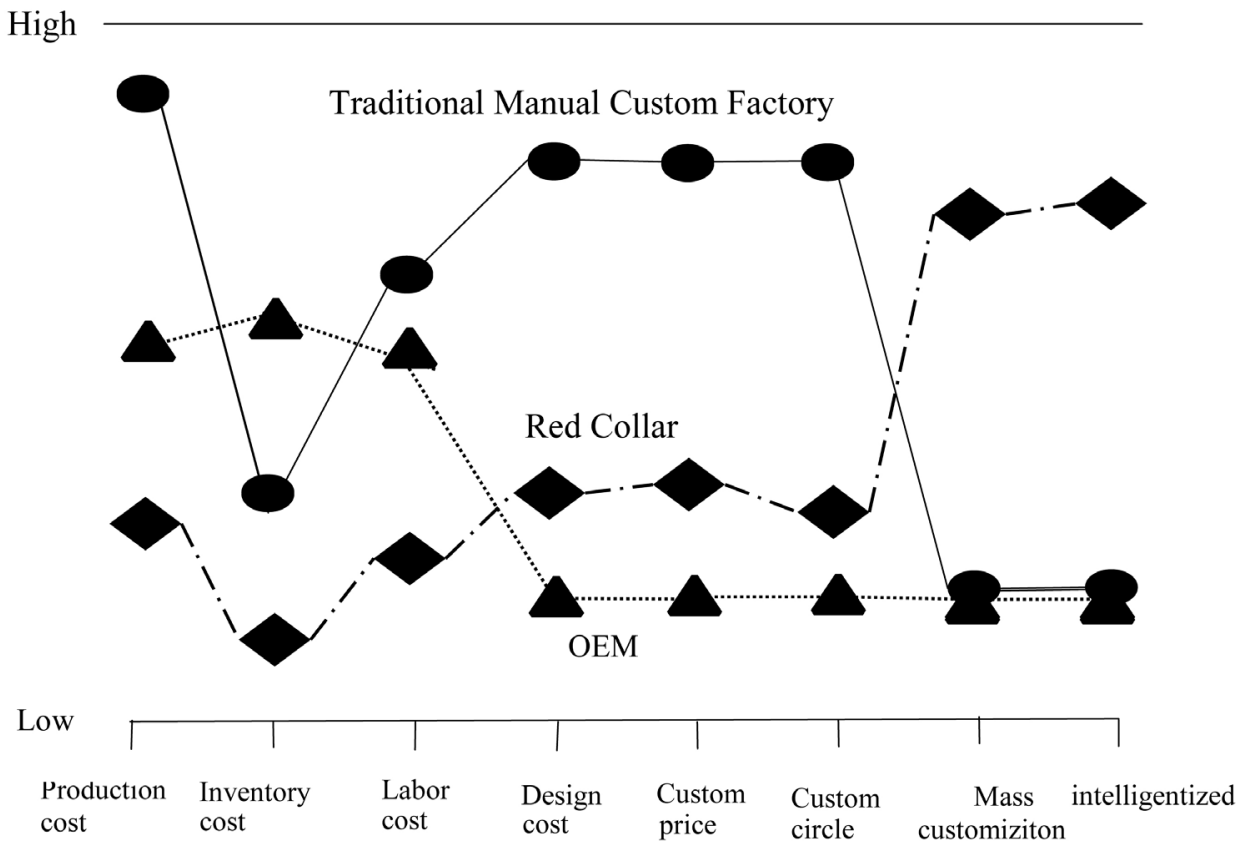

Figure 4. The strategy canvas of red collar.

production efficiency of enterprise.

While how to realize the transformation of traditional clothing manufacturing enterprise? There are some advices below.

First, pay attention to the personalized requirement of the customers. With the rapid development of economy and society, people's level of requirement improved. More and more people are concerned about the quality of life. The demand of personalized become the key to open the door of the new market. OEM's undifferentiated production in mass can't meet the personalized demand of customers. It will lose the superiority in market competition eventually. Node management of RC, in charge of the customer from point to point, is meeting the trend of social development.

Second, optimize the supply chain to improve production efficiency. In the past, the intermediate step between the customer and factory was difficult to express the real demand of the customers and delayed the production at the same time. The industry chain of RC has been optimized to improve the production efficiency, so that the production circle is shorten from $3-6$ months to 7 working days.

Third, strengthen the innovation of technology. Represented by manufacturing industry in China, the enterprises is setting off a trend of removing outside. South-east Asian countries, such as Vietnam and Myanmar, are undertaking the transfer from China in lower wages. The advantage of the labor cost of OEM has decreased significantly, so that the companies of OEM have to transfer from labor-intensive to technology-intensive to survive in the market competition.

RC has explored a way for personalized customization with mass-production through combining the cloud computing, Internet of things and large data with modern manufacturing industries. Zhang Yunlan says, RC is going to be a plat- 
form-based firm, as Tmall and Jingdong, to make the entrance for the personalization. Taking the model of $\mathrm{C} 2 \mathrm{M}$ as the carrier and the custom as the core, $\mathrm{RC}$ has developed cross-industry cooperation in various areas to make up business ecosystem with the parties involved in value creation, value delivery and value realization. And that is the higher level of the development goal and direction of RC.

\section{References}

Anonymous 佚名 (2016a). Break the road of the Development of Red Collar 破解红领 发展之道. Textile Apparel Weekly, No. 2, 22-23.

Anonymous 佚名 (2016b). “Internet+" Clothing Customization, Realize the Practice of Mass Customization of Red Collar in Qing Dao Based on Informationization and Industrialization “互联网+”服装定制一一青岛红领基于两化融合实现大批量定制的实 践. China Quality, No. 4, 20-24.

Chai Chunlei, QiuYiwu, \& Yu Liying 柴春雷, 邱懿武, 俞立颖 (2014). Business Innovation Design 商业创新设计. Wuhan: Huazhong University of Science and Technology Press.

Ji Mi 吉宓 (2007). Business Model and Blue Ocean Strategy 商业模式和蓝海战略. Business (Review), No. 10, 45-47.

Kim, W. C., \& Mauborgne, R. (2005). Blue Ocean Strategy: How to Create Uncontested Market Space and Make the Competition Irrelevant. Boston, MA: Harvard Business School.

Liu Meiqi, \& Zhang Yuting 刘媚琪, 张宇婷 (2015). Red Collar Suit: A Revolution in the Personalization 红领西装: 一场个性化定制的革命. China Brand, No. 2, 62-64.

Pan Dongyan 潘东燕 (2014). Red Collar: Subversives of Manufacturing? 红领: 制造业 颠覆者? CEIBS Business Review, No. 8, 76-83.

Xie Dandan 谢丹丹 (2016). "Model of Red Collar": From Factory to Customized Platform “红领模式”: 从工厂到定制平台. SINO Foreign Management, No. 3, 96-98.

Xu Ting, Chen Libiao, \& Cheng Shuping 许婷, 陈礼标, 程书萍 (2007). The Connotation of the Value Innovation of Blue Ocean Strategy and Case Analysis 蓝海战略的价 值创新内涵及案例分析. Science of Science and Management of S. \& T., 28, 54-58.

Zhou Luhan 周路菡 (2015). New Model of “Internet Industry” of Red Collar 红领的“互 联网工业”新模式. New Economy Weekly, No. 9, 23-26. 
Submit or recommend next manuscript to SCIRP and we will provide best service for you:

Accepting pre-submission inquiries through Email, Facebook, LinkedIn, Twitter, etc. A wide selection of journals (inclusive of 9 subjects, more than 200 journals)

Providing 24-hour high-quality service

User-friendly online submission system

Fair and swift peer-review system

Efficient typesetting and proofreading procedure

Display of the result of downloads and visits, as well as the number of cited articles Maximum dissemination of your research work

Submit your manuscript at: http://papersubmission.scirp.org/

Or contact chnstd@scirp.org 